\title{
Correction to: Efficacy and safety of galcanezumab for preventive treatment of migraine: a systematic review and meta-analysis
}

\author{
Xiuyuan $\mathrm{Zhao}^{1} \cdot$ Xiaolin $\mathrm{Xu}^{2} \cdot$ Qingyun $^{\mathrm{Li}^{2}}$
}

Published online: 8 February 2021

(c) The Author(s) 2021

\section{Correction to: Journal of Neurology https://doi.org/10.1007/s00415-020-09707-5}

The authors would like to correct errors in the publication of their original article. The corrected details are given below:

On page 2 in the second paragraph, the date of first marketing authorization of galcanezumab needs to be corrected to September 2018. The correct sentence is:

"Thus, anti-CGRP monoclonal antibodies are used as the prophylactic treatments for migraine. Galcanezumab was authorized in the USA in September 2018."

On page 10 in the fourth paragraph it is stated, that seven patients in the galcanezumab $240 \mathrm{mg}$ group of EVOLVE-2 suffered from acute myocardial infarction and transient ischemic attack, while in fact the source cited states that one patient reported acute myocardial infarction and one patient reported transient ischemic attack. The correct sentence is:

"In the galcanezumab $240 \mathrm{mg}$ group of EVOLVE-2, one patient reported acute myocardial infarction and one patient reported transient ischemic attack [15]".

On page 10 in the fourth paragraph, the authors would like to delete the following phrase:

"Meanwhile, hypertension was observed in five patients in the clinical trials, but it remains uncertain if these patients had hypertension before enrollment [33]."

In the original text, the place that needs to see Fig. 5 is changed to Fig. 8. The place that needs to see Fig. 6 is changed to Fig. 5. The place that needs to see Fig. 7 is changed to Fig. 6 . And the place that needs to see Fig. 8 is changed to Fig. 7.

Furthermore, in Fig. 5 the x-axis had to be moved to correctly reflect the data; please find the revised Fig. 5 here:

The revised Fig. 5 used the rigorous data published on the clinical trial website, and carefully checked the operation on Revman at each step.

As a result, the conclusion needs to be changed to "Our meta-analysis suggested galcanezumab had favorable influence on the increase in $\geq 50 \%$ response, $\geq 75 \%$ response, and $100 \%$ response. As for the control group also has a high $\geq 50 \%$ response, $\geq 75 \%$ response, and $100 \%$ response, the reason may be to comfort the psychological function of the patients."

Lastly, Figs. 6-8 have been mislabeled by accident; please find the corrected text references and figure labels below:

Figure 6 displays the adverse effects; the label for Fig. 6 should read:

"Fig. 6 Adverse events for galcanezumab (RR, risk ratio; CI, confidence interval)".

Figure 7 displays the anti-drug antibodies data; the label for Fig. 7 should read:

"Fig. 7 The development of anti-drug antibodies (ADA) to galcanezumab (RR, risk ratio; CI, confidence interval)".

Figure 8 displays funnel plots; the label for Fig. 8 should read:

"Fig. 8 Funnel plot of the publication bias".

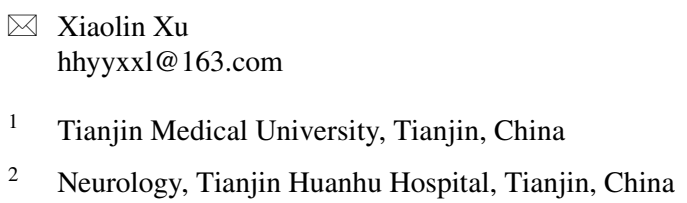




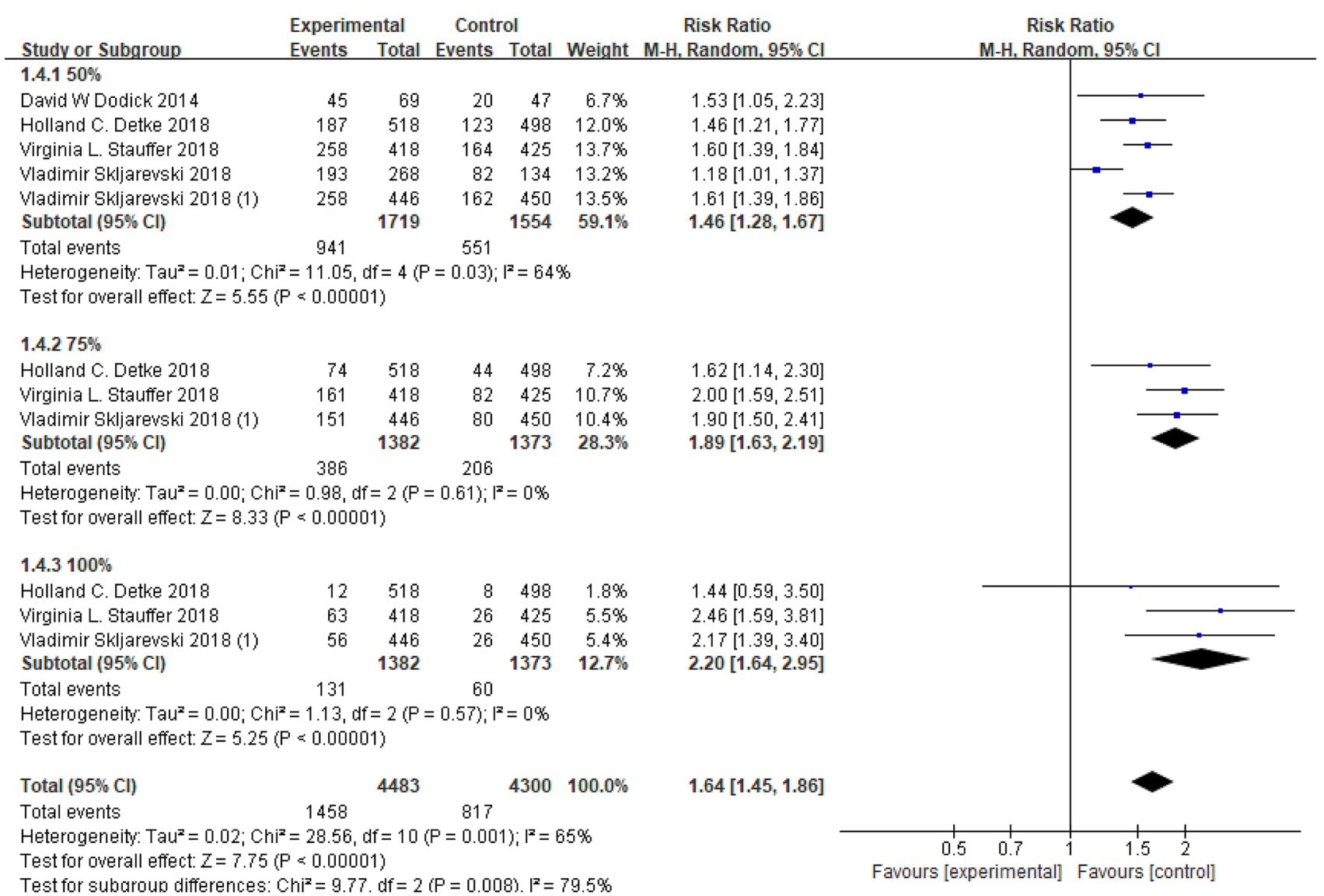

Fig. 5 The 50\%, 75\% and 100\% responder rates of the reduction from baseline in MMDs (RR, risk ratio; CI, confidence interval)

Open Access This article is licensed under a Creative Commons Attribution 4.0 International License, which permits use, sharing, adaptation, distribution and reproduction in any medium or format, as long as you give appropriate credit to the original author(s) and the source, provide a link to the Creative Commons licence, and indicate if changes were made. The images or other third party material in this article are included in the article's Creative Commons licence, unless indicated otherwise in a credit line to the material. If material is not included in the article's Creative Commons licence and your intended use is not permitted by statutory regulation or exceeds the permitted use, you will need to obtain permission directly from the copyright holder. To view a copy of this licence, visit http://creativecommons.org/licenses/by/4.0/. 